\title{
La sanción por falta de idoneidad en la prestación de servicios de salud ¿Puede llegar a restringir el derecho de objeción de conciencia? El caso del aborto terapéutico.
}

\author{
Diana Milagros De la Cruz Carranza ${ }^{1}$
}

\begin{tabular}{ll}
\hline INFORMACIÓN DEL ARTÍCULO & RESUMEN \\
\hline $\begin{array}{l}\text { Historia del artículo: } \\
\text { Recibido el } 17 \text { de junio } 2020\end{array}$ & El presente trabajo aborda el análisis de un posible conflicto de derechos en la atención \\
Aceptado el 17 julio 2020 & de casos de aborto terapéutico. Por un lado, el derecho a la objeción de conciencia del \\
& médico tratante, y por otro, el derecho a la idoneidad en la prestación de servicios de \\
\hline Palabras clave: & salud. Este análisis se realiza a partir de la Resolución $N^{\circ} 1884-2017 / S P C-I N D E C O P I$ \\
Objeción de conciencia & (Caso Clínica El Golf), mediante el cual se sanciona a dicho nosocomio por la negativa \\
Idoneidad & de uno de sus médicos, a realizar un aparente aborto terapéutico, encuadrando dicha \\
Protocolo de aborto terapéutico & conducta en falta de idoneidad del servicio de salud. Si bien la resolución no aborda el \\
Prestación de servicios de salud & derecho a la objeción de conciencia, se pretende establecer criterios objetivos para \\
& resolver un posible conflicto, partiendo de la hipótesis de que, cuando el \\
& procedimiento médico atenta contra la vida y salud de las personas, entonces es \\
& posible que el profesional médico pueda ejercer su derecho a la objeción de conciencia \\
& sin afectar la calidad e idoneidad en la prestación de sus servicios.
\end{tabular}

The sanction for lack of suitability in the provision of health services Can it restrict the right of conscientious objection? The case of therapeutic abortion.

\section{ABSTRACT}

Keywords:

Conscientious objection

Suitability

Therapeutic abortion protocol

Provision of health services

\begin{abstract}
This work addresses the analysis of a possible conflict of rights in the care of cases of therapeutic abortion. On the one hand, the right to conscientious objection of the treating physician, and on the other, the right to suitability in the provision of health services. This analysis is carried out based on Resolution No. 1884-2017 / SPC-INDECOPI (El Golf Clinic Case), through which the hospital is sanctioned for the refusal of one of its doctors to carry out an apparent therapeutic abortion, framing such conduct in the absence of suitability of the health service. Although the resolution does not address the right to conscientious objection, it is intended to establish objective criteria to resolve a possible conflict, based on the hypothesis that, when the medical procedure threatens the life and health of people, then it is possible that the medical professional can exercise his right to conscientious objection without affecting the quality and suitability in the provision of his services.
\end{abstract}

\footnotetext{
${ }^{1}$ Abogada egresada de la Universidad Católica Santo Toribio de Mogrovejo. Investigadora Independiente. Chiclayo, Perú. E-mail: diana.carranza.16@hotmail.com, ORCID: https://orcid.org/0000-0002-8322-3343
} 


\section{Sumario}

Introducción. 1. El derecho a la objeción de conciencia y los ámbitos de su ejercicio. 1.1. El derecho de libertad de conciencia como su fundamento. 1.2. El derecho a la objeción de conciencia. 1.3. La objeción de conciencia en el ámbito específico de la prestación de servicios de salud. 2. El deber de idoneidad en la prestación de servicios de salud. 2.1. El derecho del consumidor y la relación de consumo. 2.2. Idoneidad de productos y servicios. 2.3. Caso: Clínica El Golf. 3. El aborto terapéutico desde la perspectiva de la objeción de conciencia en los servicios privados de salud. 3.1. El aborto terapéutico en la legislación peruana. 3.2. Objeción de conciencia y aborto terapéutico. 3.3. Criterios objetivos para ejercer debidamente el derecho a la objeción de conciencia. Conclusiones. Bibliografía

\section{Introducción}

En el fallo recogido en la Resolución N 1884-2017/SPCINDECOPI, la Sala de Protección al Consumidor de Indecopi, sancionó a Sistema de Administración Hospitalaria S.A.C (Clínica El Golf,) por haber infringido los artículos $18^{\circ} ; 19^{\circ}$ y $67^{\circ}$ numeral $1^{\circ}$ del código de protección y defensa del consumidor, en el extremo de no haber tramitado debidamente la solicitud de aborto terapéutico de la denunciante. Se determinó que la clínica infringió el deber de idoneidad en la prestación del servicio de salud en la medida que no valoró el daño a la salud mental de la gestante (causal por la que su psiquiatra - ajeno a la clínica - recomendó el aborto). Cabe señalar que, el ginecólogo tratante - personal de la clínica - había considerado que el estado de salud de la denunciante no se encontraba en riesgo, por lo que no había mérito para indicar un procedimiento de aborto.

En el Perú, la Guía Técnica Nacional para la estandarización del procedimiento de la Atención Integral de la Gestante en la Interrupción Voluntaria por Indicación Terapéutica del Embarazo menos de 22 semanas con consentimiento informado en el marco de lo dispuesto en el artículo $119^{\circ}$ del Código Penal (protocolo aborto terapéutico), aprobada por Resolución Ministerial N 486-2014/MINSA, permite que la gestante pueda solicitar la interrupción de su embarazo menor de 22 semanas cuando este sea el único medio para salvar su vida o para evitar en su salud un mal grave y permanente. Dicha guía regula once supuestos en los que se amerita evaluar la interrupción terapéutica del embarazo. Sin embargo, algunos de estos supuestos han sido cuestionados a nivel médico y jurídico, no solo porque no serían suficientes para justificar el aborto, sino porque dan lugar a un amplio margen de interpretación, pudiendo llegar a utilizarse en casos no justificados (por ejemplo, solo hace falta un diagnóstico de "depresión recurrente" de la gestante, para realizar un aborto).

En este contexto, podemos encontrar a profesionales de salud que, aun considerando que no es necesario realizar el aborto, se pueden ver compelidos a hacerlo, pues, de lo contrario, el establecimiento de salud o ellos mismos, podrían recibir una sanción enmarcada en una supuesta falta de idoneidad. Y en este supuesto ¿cuál sería el mecanismo de defensa del profesional de la salud?

A partir de este caso, analizaremos los límites del deber de idoneidad en la prestación de servicios privados de salud, y si ello compromete o limita el ejercicio del derecho a la objeción de conciencia de aquellos médicos que se abstienen de realizar prácticas que involucran el derecho a la vida del concebido, por una forzosa aplicación del Protocolo del Aborto Terapéutico. Se busca, por ello, determinar los criterios objetivos a tomar en cuenta para ejercer el derecho a la objeción de conciencia cuando este se encuentra en un aparente conflicto frente a la idoneidad de la prestación de servicios de salud.

El presente trabajo se ha estructurado en tres partes. En la primera se analizará el derecho a la objeción de conciencia, teniendo en cuenta la libertad de conciencia como su fundamento más próximo. Se abordarán los distintos ámbitos de su ejercicio, específicamente en el ámbito de salud. En la segunda, se analizará la relación de consumo en los servicios de salud, para poder determinar los criterios de idoneidad expedidos por Indecopi en un producto y/o servicio. Finalmente, en la tercera parte, se analizará el Protocolo de Aborto Terapéutico, regulado en la Resolución Ministerial $N^{\circ} 486-2014 /$ MINSA, para poder evaluar si existe o no una afectación al deber de idoneidad en los servicios de salud; en aquellos casos en donde el profesional médico decide abstenerse de realizar dicha práctica en atención a su derecho a la objeción de conciencia.

\section{EL DERECHO A LA OBJECIÓN DE CONCIENCIA Y LOS ÁMBITOS DE SU EJERCICIO}

1.1. El derecho de libertad de conciencia como su fundamento

Antes de introducirnos en el tema de la objeción de conciencia resulta preciso- a efectos de una mejor comprensión- estudiar el derecho de libertad de conciencia como su fundamento más próximo o inmediato. Llamazares (2007) define a la conciencia como "la capacidad o facultad para percibir la propia identidad personal como radical libertad, en lo que 
cada uno es similar y distinto de lo otro y de los otros (...), de sus posibilidades y de sus límites (...)" (p.17). Podemos sostener que tanto la libertad como la conciencia son facultades propias del ser humano, de tal manera que es el hombre el único ser capaz de actuar con libertad haciendo previamente una valoración de la realidad fundada en la moral, que no solo le permita orientar su conducta, sino también descubrir cuáles son sus límites y las responsabilidades que traen consigo dichos actos.

Así, la libertad de conciencia está referida al ámbito más íntimo del ser humano como un ser libre y capaz de construir su propio juicio o concepto de moralidad fundadas en determinados valores que constituyan directrices en su actuar.

En el mismo sentido, Souto Paz (citado en Mosquera, 2005) manifiesta que la libertad de conciencia es el derecho a "actuar de acuerdo con su propia ideología o creencia y a oponerse a hacer algo que contradice radicalmente esa ideología o creencias, aunque sea impuesto legalmente" (p.135). El autor agrega en la referida definición que, es la libertad de conciencia que toda persona posee- la que nos permite objetar a la realización de ciertos actos que resultan contrarios a ese juicio de valores que vamos formando o construyendo en nuestro interior, aun cuando la realización de dicho acto provenga de un imperativo legal.

Por otro lado, Vinces (2015) sostiene que "la libertad de conciencia protege el juicio práctico de moralidad" (pp.4-5), es decir que protege el comportamiento o la acción que se realiza siguiendo el sistema moral que cada persona va creando en base a determinados valores. En esta definición, el autor aporta algo novedoso: el elemento práctico de la manifestación de esta libertad, pues es el sujeto quien al realizar una valoración o juicio crítico de determinados hechos, evalúa si la realización de este va acorde o no con dicha valoración. Así pues, el contenido del derecho de libertad de conciencia, según Vinces (2015):

Abarca dos dimensiones: en primer lugar, una dimensión positiva, que se traduce en la libertad de toda persona de formar libremente su conciencia y de actuar conforme a ella, y en segundo lugar, una dimensión negativa, que determina que nadie puede ser obligado contra los dictados de su conciencia (p.10).

Aunado a ello, la libertad de conciencia como fundamento del derecho a la objeción de conciencia, según Navarro (2004) "es propia de la escuela del derecho natural, es decir, aquella que sostiene la existencia de valores anteriores a las normas, y que están por encima de ellas (...), y será digna de obediencia, si es acorde con aquellos valores" (p.29). De ello podemos afirmar entonces que, la concepción de valores que cada persona crea proviene del derecho natural, el cual se posiciona en un escalón más alto que la ley positiva y que, consecuentemente esta no debería contradecirlo; toda vez que, el hombre por su propia dignidad actuará movido por sus convicciones personales de acuerdo a lo que su conciencia y valores le ordenen.

Sin embargo, es preciso señalar que, la libertad de conciencia no solo deriva o emana del derecho natural, sino que también es posible que el sujeto se adhiera a otras teorías o doctrinas de la moral para explicar a partir de ella sus valores o creencias, pudiendo así justificar sus acciones desde su propia autonomía moral.

Así pues, podríamos definir la libertad de conciencia como el derecho que posee toda persona de asumir su propio sistema moral que le permita diferenciar lo bueno de aquello que no lo es, aun cuando una conducta sea socialmente aceptable, y que en función a ello puedan dirigir o direccionar su actuar. Cabe señalar que este sistema moral se encuentra basado en la racionalidad de persona, y por ello se corresponde con un sistema objetivo de valores impregnando en la naturaleza del hombre, la que se entiende como principio de operaciones.

Esta libertad se encuentra reconocida en el artículo 2.3 de la Constitución Política del Perú (CPP), la misma que sostiene que:

"Toda persona tiene derecho (...) A la libertad de conciencia y de religión, en forma individual o asociada. No hay persecución por razón de ideas o creencias. No hay delito de opinión. El ejercicio público de todas las confesiones es libre, siempre que no ofenda la moral ni altere el orden público" 2

En el citado artículo, se hace referencia a los dos ámbitos de la libertad: de conciencia y de religión, tal y como se ha utilizado en la redacción del artículo 12.1 de la Convención Americana de Derechos Humanos, aun cuando Mosquera (2005) señala que "la libertad de conciencia permite desarrollar la propia libertad de pensamiento, ideología y religión, pues la conciencia es el crisol en el que se producen todos los cambios del pensamiento, la ideología y la religión" (p.135).

El Tribunal Constitucional (TC) ha señalado que "el derecho a la libertad de conciencia supone el derecho de toda persona de formarse libremente la propia

${ }^{2}$ Artículo 2.3 de la Constitución Política del Perú. 
conciencia, de manera tal que aquella formación se vea exenta de intromisiones de cualquier tipo (STC. 2001, fd. 3). Se trata pues, de una "facultad del individuo de actuar y realizar su vida en consonancia con su personal concepción deontológica. En otras palabras, es la libertad de la persona de poseer su propio juicio ético o moral y de actuar conforme a dicho juicio en su entorno social o en el contexto en el que se desenvuelve" (STC. 2009, fd. 10)

Cabe señalar que tanto la jurisprudencia como la doctrina, establecen una distinción entre libertad de conciencia y libertad religiosa, definiéndose esta última como:

(...) la capacidad de toda persona para autodeterminarse de acuerdo con sus convicciones y creencias en el plano de la fe religiosa, así como para la práctica de la religión en todas sus manifestaciones, individuales o colectivas, tanto públicas como privadas, con libertad para su enseñanza, culto, observancia y cambio de religión" (STC. 2009, fd.11)

El derecho a la libertad de conciencia resulta ser el fundamento más próximo del derecho a la objeción de conciencia, pues a través de la manifestación de esta libertad el individuo exterioriza ese juicio de valores que interiormente ha construido sobre un determinado tema. Esto supone a su vez -según su dimensión negativa- que nadie puede ser obligado a actuar en contra de ese sistema de valores.

Ahora bien, en los casos en los que "se plantea el dilema de optar entre el deber de obediencia que impone la norma legal (...) y el deber de resistirla que sugiere la norma moral" (Navarro-Valls, 2007, p.144), se activa el llamado, derecho a la objeción de conciencia, que puede entenderse como un derecho, derivado necesariamente del contenido del derecho de libertad de conciencia.

Así lo ha determinado el TC (2001, fd.6):

Habiéndose considerado que en virtud de la libertad de conciencia, toda persona tiene derecho a formar su propia conciencia, no resulta descabellado afirmar que uno de los contenidos nuevos del derecho a la libertad de conciencia esté constituido, a su vez, por el derecho a la objeción de conciencia, porque de qué serviría poder autodeterminarse en la formación de las ideas si no es posible luego obrar (o dejar de obrar) conforme a los designios de esa conciencia. No permitirle al individuo actuar conforme a los imperativos de su conciencia, implicaría que el derecho a la formación de esta careciera de toda vocación de trascendencia, pues sucumbiría en la paradoja perversa de permitir el desarrollo de convicciones para luego tener que traicionarlas o reprimirlas con la consecuente afectación en la psiquis del individuo $y$, por ende, en su dignidad de ser humano.

\subsection{El derecho a la objeción deconciencia}

Se define el derecho a la objeción de conciencia como "la negativa del individuo, por razones de conciencia, al cumplimiento de una obligación que, en principio, le resulta jurídicamente exigible, sea que esta provenga de un mandato legal, una resolución judicial, un acto administrativo, o un contrato" (Díaz, 2004, p.167). Por su parte, María Ciaurriz (citado en Navarro, 2004) lo define como "el comportamiento individual, basado en los motivos de conciencia y contrario a la norma jurídica estatal". Finalmente, Martínez (2007) sostiene que la objeción de conciencia "constituye así el rechazo moral a participar en ciertos actos debido a la incompatibilidad de los valores de una persona con los de la mayoría de los ciudadanos y/o a la incompleta o insuficiente comprensión de los valores de esta" (p. 216).

Entonces, podemos afirmar que la principal característica de la objeción de conciencia radica en su naturaleza excepcional, por lo tanto, en ningún caso podría ser una práctica generalizada, ya con su ejercicio se busca la protección de una minoría, que en determinadas circunstancias considera que cumplir con un deber jurídico le resultaría contrario a sus valores. En ese sentido, y atendiendo a su naturaleza, podemos sostener que el ejercicio de la objeción de conciencia se evidenciará en situaciones límites y muy específicas.

Asimismo, el ejercicio de este derecho no solo supone una conducta omisiva e individual del sujeto en el que se abstiene de obedecer o cumplir un mandato imperativo, sino que, dicho incumplimiento no genera ningún tipo de responsabilidad legal en el sujeto. Se trata así, de una excepción a la regla general de cumplimiento.

Para que se aplique esta excepción, deben cumplirse los siguientes requisitos:

a) Conducta exigida al objetor:

Como señala Martínez (2007), la objeción de conciencia, necesariamente "ha de estar relacionada con algún comportamiento clave del marco moral de la persona que objeta" (p.217). En tal sentido, se debe exigir previamente al objetor, la realización de una conducta, la misma que puede provenir de un mandato legal, una resolución judicial, un acto administrativo o de un contrato. Salazar (2013) manifiesta que la 
conducta exigida al autor pueden consistir en: (i) dar, este comportamiento implica un entregar, conceder $u$ otorgar algo, tal es el caso del pago de impuestos que tengan un fin bélico. (ii) un hacer positivo, este supuesto exige la realización de una conducta por parte del sujeto, el cual puede consistir en la prestación del servicio militar, la práctica de un aborto o el trabajar los días sábados. (iii) un hacer pasivo, ello implicaría un acción tácita del objetor como por ejemplo el recibir educación formal o recibir determinados contenidos, y finalmente (iv) un no hacer, lo que supone una conducta omisiva por parte del objetor, como la prohibición de uso de velo islámico u otros símbolos religiosos en ámbitos públicos.

b) Fuente normativa:

La fuente de donde nace la obligación para el objetor puede nacer de una ley, un acto administrativo, un reglamento, o un contrato. Al respecto, Díaz (2004) sostiene que este derecho supone el rechazo por parte del objetor en el cumplimiento de una obligación "jurídicamente exigible, sea que esta provenga de un mandado legal, una resolución judicial, un acto administrativo o un contrato (...) fundada en razones axiológicas, de contenido religioso o ideológico (p.167). La fuente normativa- como requisito para alegar el derecho a la objeción de conciencia- debe ser entendida en el sentido más amplio de la palabra, es decir como todo aquello que produce un cambio en la esfera jurídica del objetor.

\section{c) Desobediencia Jurídica:}

Lo que pretende el objetor al ejercer su derecho a la objeción de conciencia es que se le exonere del cumplimiento de una obligación, sin que ellos tenga como consecuencia la imposición de una sanción (lo que sucedería en cualquier otro caso en el que se incumpla la norma fuera del marco del derecho mencionado). Así pues, el efecto de la conducta también es individual y se relaciona directamente con la norma, sin pretender modificarla, como ocurre en el caso de la desobediencia civil (Salazar, 2013).

d) Necesidad del sacrificio del objetor de conciencia. Gómez (2013) sostiene que "es necesario, que la realización de la conducta recogida en la ley, que se quiere objetar, produzca un grave perjuicio para la conciencia del objetor, no solo una mera disconformidad" (p.5). El daño a la conciencia moral del

${ }^{3}$ Artículo 4- Ley N²9635-Ley de Libertad Religiosa peruana (LLR) ${ }^{4}$ Cfr. Cavada, J., Weidenslaufer, C. y Harris, P. (2016) Profesionales o instituciones que pueden ejercer objeción de conciencia frente a la individuo debe ser evidente y por ello, pasible de demostración. Se debe verificar que en el transcurso de su vida el objetor ha asumido un determinado tipo de conducta (habitualidad) y que no se trata de una reciente voluntad de incumplimiento. Es necesario exigir la coherencia del objetor con su negatividad en el cumplimiento de la obligación.

Si bien el derecho a la objeción de conciencia no goza de un reconocimiento constitucional expreso, la Ley $\mathrm{N}^{\circ}$ 29635-Ley de Libertad Religiosa peruana (LLR) sí reconoce a este derecho en el artículo 4:

La objeción de conciencia es la posición de un individuo al cumplimiento de un deber legal, en razón de sus convicciones morales o religiosas. Se ejerce la objeción de conciencia cuando alguien se ve imposibilitado de cumplir una obligación legal por causa de un imperativo moral o religioso, grave o ineludible, reconocido por la entidad religiosa a la que pertenece. ${ }^{3}$

El legislador ha optado por incluir a la objeción de conciencia en la Ley de Libertad Religiosa; tal vez porque en su texto alude a las convicciones religiosas como uno de los fundamentos o razones para que el individuo pueda objetar un deber legal.

En ese contexto, la objeción de conciencia busca proteger ese conjunto de creencias religiosas o morales como una condición intrínseca e individual de casa persona, no obstante en países como Chile, EE.UU y Uruguay han trasladado este atributo al ámbito institucional, dando lugar así a la objeción de conciencia institucional. (Cavada, Weidenslaufer y Harris, 2016). ${ }^{4}$

Así pues, esta objeción correspondería ejercerla únicamente a las instituciones prestadoras de servicios, por ejemplo aquellas clínicas privadas que como institución consideran que determinadas prácticas médicas resultan contrarias su ideario (estatuto) o valores institucionales, por lo que la regulación de este derecho buscaría que la negatividad de los profesionales de salud -que pertenecen a ciertas instituciones privadas- a realizar prácticas como el aborto o la eutanasia sea legítima y consecuentemente no sean susceptible de algún tipo de sanción como multas. En ese sentido, cabe precisar que, en la Legislación peruana no se encuentra regulada la objeción de conciencia institucional.

1.3 Objeción de conciencia en el ámbito específico de la prestación de salud.

interrupción del embarazo: derecho comparad. Biblioteca del congreso nacional de chile, p. 7-8) 
Si bien la objeción de conciencia puede ejercerse en distintos ámbitos (servicio militar, laboral, etc.), esta vez nos referiremos únicamente al ámbito de la prestación de servicios de salud.

Martínez (2007) afirma que

"la objeción de conciencia en medicina es la negativa de un profesional a ejecutar un acto médico o a cooperar directa o indirectamente a su realización porque a pesar de haber sido aprobado por las normas legales, es considerado por el profesional como contrario a la moral, a los usos deontológicos o las normas religiosas" (p.220).

Así pues, la objeción de conciencia del médico es:

Muestra del pluralismo ético y una acción de gran dignidad ética cuando las razones aducidas son serias, sinceras y constantes y se refieren a cuestiones graves o fundamentales. En estos casos, no hacer objeción de conciencia puede ser equivalente a traicionar su propia identidad y conciencia, a manchar la dignidad del médico en cuanto agente moral.

Un bien jurídico básico reconocido por ley porque significa y manifiesta el respeto civil debido a la identidad moral de las personas. (Martínez, 2007, p.220)

En tal sentido, la objeción de conciencia en la prestación de servicios de salud, supone reconocer que el profesional médico cuenta con determinados valores que guían su actuar, no solo en el ámbito personal, sino en todo aquel que se le exija la realización de un comportamiento. Así pues, existirán casos puntuales en los que el profesional médico se enfrente a situaciones en donde su sistema de valores no guarde compatibilidad con determinadas prácticas 0 tratamientos médicos, generándose una colisión de derechos, por un lado el profesional médico que alega el ejercicio de su derecho a la objeción de conciencia, mientras que por otro lado, se encuentra el derecho de la paciente de recibir el tratamiento que solicita (consumidor).

\section{EL DEBER DE IDONEIDAD EN LA PRESTACIÓN DE SERVICIOS DE SALUD}

\subsection{El derecho del consumidor y la relación de consumo}

En nuestro modelo económico (de Economía Social de Mercado), el consumidor ocupa un papel relevante y

\footnotetext{
${ }^{5}$ Cfr. Artículo 65 de la Constitución Política del Perú: El Estado defiende el interés de los consumidores y usuarios. Para tal efecto garantiza el derecho a la información sobre los bienes y servicios
}

merece especial protección del Estado. La Constitución Política establece que es papel del Estado defender el interés de los consumidores y usuarios, velando especialmente porque se le brinde la información adecuada, sobre los bienes y servicios a los que accede en el mercado, velando principalmente por su salud y seguridad ${ }^{5}$.

Por su parte, Stiglitz (1993) afirma respecto al derecho del consumidor que, "es un sistema global de normas, principios, instituciones y medios instrumentales consagrados por el ordenamiento jurídico, para procurar al consumidor una posición de equilibrio dentro del mercado en sus relaciones con los empresarios" (p.67).

Los derechos del consumidor se despliegan especialmente en una relación de consumo, sin embargo:

no puede ser entendido como un comportamiento estático, delimitado rígidamente por un estatuto especial de consumo y restringido a las relaciones de este tipo, sino que, por naturaleza, siendo un derecho de tercera generación, abarca un espectro más amplio a considerar en su conceptualización y tratamiento, que tiene como nota distintiva su marcada interrelación con otros derechos de su misma categoría, como el derecho ambiental yel desarrollo humano, y cuya fundamentación moral descansa en los principios de solidaridad y equidad interregional e intergeneracional. (Pérez, 2004, p.6)

Lo cierto es que, consumidores y proveedores, "ambos protagonistas, a su vez, adquieren su calidad de tales a través de su integración en una relación de consumo" (Cajarville, s.f, p.152). Por lo tanto, existe entre ambos una relación de dependencia en tanto que solo se podrá hablar de consumidor cuando previamente hay un proveedor, y solo se podrá ser proveedor de algún consumidor.

El artículo IV del Título Preliminar del Código de Protección y defensa del consumidor ${ }^{6}$, define al consumidor como:

1.1 Las personas naturales o jurídicas que adquieren, utilizan o disfrutan como destinatarios finales productos o servicios materiales e inmateriales, en beneficio propio o de su grupo familiar o social, actuando así en un ámbito ajeno a una actividad empresarial o profesional. No se considera consumidor para efectos de este

que se encuentran a su disposición en el mercado. Asimismo vela, en particular, por la salud y la seguridad de la población. ${ }^{6}$ LEY № 29571, Código de Protección y defensa del consumidor 
Código a quien adquiere, utiliza o disfruta de un producto o servicio normalmente destinado para los fines de su actividad como proveedor.

1.2 Los microempresarios que evidencien una situación de asimetría informativa con el proveedor respecto de aquellos productos 0 servicios que no formen parte del giro propio del negocio.

1.3 En caso de duda sobre el destino final de determinado producto o servicio, se califica como consumidor a quien lo adquiere, usa o disfruta.

Como puede apreciarse, la norma considera consumidor al destinatario final del bien o servicio, fuera del ámbito profesional. Establece la excepción con los microempresarios en situación de asimetría. También será considerado consumidor aquel que usa o disfruta los bienes o servicios contratados.

Por otro lado, los sujetos que califican como proveedores dentro de la relación de consumo pueden ser tanto personas naturales como jurídicas, siempre que de manera habitual suministran productos o prestan servicios a los consumidores. En ese sentido, se consideran proveedores -según la ley- a los distribuidores, productores, importadores, prestadores y todos aquellos sujetos que participan en la cadena productiva del bien o servicio hasta que llegue a su destinatario final. Respecto a los sujetos que participan en la cadena productiva, estos "mantienen obligaciones diferenciadas frente al consumidor, atendiendo a su posición y participación (...), el fabricante debe garantizar la idoneidad de los productos que lanza al mercado $y$, por su parte, el comercializador debe verificar la idoneidad de estos antes de ofrecerlos. (Indecopi, 2016, p.8). Una clínica que presta servicios de salud califica entonces como proveedora y por tanto, se le aplican las normas de protección previstas en la ley. Por otro lado, los trabajadores dependientes se encuentran sujetos a las disposiciones del empleador y se encuentran obligados al cumplimiento de las prestaciones en las condiciones establecidas. Este dato es relevante, para analizar los alcances del deber de idoneidad del servicio prestado.

\subsection{Idoneidad de productos y servicios}

Como ya se ha mencionado, la protección al consumidor -en la legislación peruana- se desarrolla a través de un sistema de control y fiscalización administrativa, cuya competencia le es atribuida al Indecopi. En tal sentido, el Indecopi es el ente especializado en resolver las cuestiones formuladas por los consumidores contra los proveedores, estableciendo en sus resoluciones criterios que ayuden a una mejor interpretación de la Ley $N^{\circ} 29571$.

Una de las cuestiones que ha merecido mayor fiscalización y pronunciamiento por parte de este ente especializado; se encuentra relacionado con el denominado deber de idoneidad. Este deber ha sido regulado en el artículo 18 del Código de protección y defensa del consumidor:

Se entiende por idoneidad la correspondencia entre lo que un consumidor espera y lo que efectivamente recibe, en función a lo que se le hubiera ofrecido, la publicidad e información transmitida, las condiciones y circunstancias de la transacción, las características y naturaleza del producto o servicio, el precio, entre otros factores, atendiendo a las circunstancias del caso. La idoneidad es evaluada en función a la propia naturaleza del producto o servicio y a su aptitud para satisfacer la finalidad para la cual ha sido puesto en el mercado. Las autorizaciones por parte de los organismos del Estado para la fabricación de un producto o la prestación de un servicio, en los casos que sea necesario, no eximen de responsabilidad al proveedor frente al consumidor.

En el mismo sentido de ideas, en la Resolución 10082013/SPC-INDECOPI, establece que la falta de idoneidad consiste en la inexistencia de esa correspondencia, es decir, ocurre cuando el proveedor defrauda las expectativas de un consumidor respecto del producto o servicio que se le ha ofrecido. (2013)

Entonces podemos sostener que, el deber de información se encuentra íntimamente ligado al deber de idoneidad, pues este implica que los consumidores tienen derecho a recibir los productos y servicios con las características que inicialmente le fueron informadas y posteriormente ofrecidas en función a la naturaleza de la operación. No obstante, en la práctica resulta un tanto difícil determinar cuándo un bien o un servicio es verdaderamente idóneo para el consumidor o cuando se ha transgredido este deber, por lo que el Indecopi es el único encargado de establecer en cada caso particular los criterio que deben seguirse con el fin de cumplir íntegramente este deber. Así pues, la reciente Resolución del Tribunal de Indecopi $N^{\circ} 1008$ 2013/SPC-INDECOPI ha establecido importantes criterios para determinar los alcances de la responsabilidad de los proveedores.

El deber de idoneidad forma parte de las obligaciones de todo proveedor. El cumplimiento de las expectativas del consumidor en relación a la calidad, uso, duración, origen, contenido y otras características propias de los productos o servicios contratados. No obstante, la 
obligación de los proveedores no supone "entregar la mejor calidad del producto o servicios disponible, sino aquel nivel de calidad ofrecido y contratado por el consumidor, tampoco es obligación del proveedor cumplir con expectativas que el consumidor se haya formado y que no guarden relación con lo pactado y con lo que, en circunstancia razonables, se esperaría del producto o del servicio". (Northcote, 2013, p.1). Por ello, es necesaria la concurrencia de otra característica, la de un consumidor razonable (Espinoza, 2016). A esto se debe agregar las circunstancias particulares en las que se desarrolla la relación de consumo, como la vulnerabilidad del consumidor, la confianza depositada en el proveedor, de acuerdo al tipo de servicio o bien que se ha ofrecido, negociado y finalmente contratado. A efectos de determinar cuándo un producto o servicio es idóneo, resulta necesario recurrir al término garantía (Art.20), el mismo que debe ser entendido como un parámetro de idoneidad. Así pues, esta garantía comprende a su vez tres tipos: garantía legal, garantía expresa y garantía implícita.

En tal sentido, la garantía será legal siempre que a través de mandato de la ley o de las regulaciones vigentes no se permita la comercialización de un producto o la prestación de un servicio sin cumplir con determinados requisitos contenidos en dicha garantía, así como tampoco se puede contratar bajo condiciones contrarias a esta garantía. Una garantía será expresa cuando los términos y condiciones expresamente ofrecidos y pactados son propios de las negociaciones entre el proveedor y el consumidor, como la publicidad, el etiquetado entre otros. Y finalmente, se entiende que existe garantía implícita cuando media el silencio del proveedor o cuando no existiendo contrato, se infiere que el producto o servicio cumplen con los fines y usos previsibles para los que han sido adquiridos por el consumidor considerando los usos y costumbres propios del mercado.

\subsection{Caso Clínica El golf ${ }^{7}$}

Si bien no se aplica desde el extremo de la objeción de conciencia, la Resolución N 1884-2017/SPC-INDECOPI, aborda el caso en el que una paciente solicita la realización de un aborto terapéutico y el médico se niega a practicarlo por no considerarlo necesario. En dicha resolución se sanciona a la Clínica El Golf por no

\footnotetext{
${ }^{7}$ Resolución N 1884-2017/SPC-INDECOPI. Tribunal de defensa no de la competencia y de la propiedad intelectual. Sala Especializada en Protección al Consumidor. Disponible en: http://www.gacetajuridica.com.pe/boletin-nvnet/img bol08/1007-2017-clinica-el-golf-aborto-terapeutico1.pdf

${ }^{8}$ La hiperémesis gravídica es la presencia de náuseas y vómitos intensos y persistentes durante el embarazo. Pueden llevar a
}

haber tramitado debidamente una solicitud de aborto terapéutico, en tanto que -a criterio del Tribunal de Indecopi- dicha clínica no garantizó a la paciente su derecho al acceso al aborto terapéutico y consecuentemente se habría infringido el deber de idoneidad en la prestación de sus servicios obstétricos (en su calidad de proveedor de servicios privados de salud).

En tal sentido, -y siguiendo la interpretación del Indecopi- un profesional de salud que labora para un clínica privada no podría negarse a practicar un aborto terapéutico, ya que dicha institución no estaría cumpliendo con su deber de idoneidad en la prestación de sus servicios, y consecuentemente sería pasible de una multa. Nos preguntamos entonces, si el médico hubiese alegado objeción de conciencia ¿el resultado hubiese sido el mismo?

Podría inferirse que, en cualquier otro caso, a un profesional se le vería limitado el ejercicio de su derecho a la objeción de conciencia, toda vez que según el Indecopi- como proveedores de servicios de salud se le debe garantizar a la paciente el acceso al aborto terapéutico y consiguientemente cumplir con su deber de idoneidad en la prestación de sus servicios.

No obstante, si bien en el caso en mención, el médico tratante no practicó el aborto terapéutico a la gestante apoyándose en criterios científicos especializados- y no en criterios morales-, esta situación nos abre un grandioso escenario para a partir de él abordar de manera hipotética el tema de la objeción de conciencia, máxime cuando el Protocolo de Aborto Terapéutico contempla causales tan amplias -como la salud mental de la madre - que pueden llegar a utilizarse en casos no justificados, comprometiendo así el derecho a la objeción de conciencia del personal médico.

\section{a. Antecedentes}

El 17 de octubre de 2014, la denunciante acudió a la clínica el golf a fin de recibir atención médica en la especialidad de ginecología, pues presentó un sangrado vaginal y náuseas. Fue atendida por el doctor Luis Alberto Almeyda Castro, quien le indicó que tenía aproximadamente seis (6) semanas de gestación. Asimismo le diagnosticó hiperémesis gravídica leve ${ }^{8}$. Con fecha 21 de octubre de 2014, acudió nuevamente a la Clínica El Golf, pues presentó dolor pélvico, y el 21

la deshidratación, pérdida de peso y desequilibrios electrolíticos. Las náuseas matutinas se refieren a las náuseas y vómitos que ocurren al inicio del embarazo. Obtenido de la página web de Medline Plus, un servicio de la biblioteca Nacional de Medicina de EE.UU, disponible en https://medlineplus.gov/spanish/ency/article/001499.htm 
de noviembre de ese mismo año, luego de ser sometida a nuevos exámenes ecográficos, se le indicó que su embarazo era riesgoso, pues se evidencia que el feto padecía de síndrome de Turner ${ }^{9}$.

Debido a que la denunciante consideraba que dicha situación ponía en riesgo su vida, solicitó al Dr. Almeyda que interrumpiera su embarazo, sin embargo, el médico indicó que ello no era posible en la medida que la patología existente no afectaba la vida de la gestante. El día 4 de diciembre de 2014, la denunciante presentó un sangrado vaginal abundante. En la Clínica El Golf, le diagnosticaron amenaza de aborto y alto riesgo obstétrico, siendo hospitalizada. Inmediatamente después, se le practicó un examen preoperatorio, de riesgo quirúrgico y una ecografía pélvica, cuya finalidad no le fue explicada.

El 9 de diciembre, le entregaron un informe de la última ecografía realizada, la cual concluía, entre otras cosas, lo siguiente: el cráneo del feto presentaba un edema generalizado y el corazón impresionaba una hipoplasia izquierda, sugiriéndole descartar alteración cromosómica con amniocentesis y un compromiso infeccioso a través de un perfil TORCH. Fue dada de alta el 10 de diciembre de 2014.

El 11 de diciembre de 2014, acudió al consultorio médico de la doctora Martha Beatriz Rondón Rondón, especialista en psiquiatría, quien le diagnosticó depresión recurrente con reacción de adaptación al estrés, y le indicó que su gestación suponía un riesgo severo para su salud mental;

El 13 de diciembre el 2014, acudió al Instituto Nacional Materno Perinatal, a fin de que se le realice un nuevo examen ecográfico, el cual concluyó que el feto presentaba malformaciones congénitas compatibles con probable cromosomopatía.

El 18 de diciembre de 2014, la denunciante presentó ante la Clínica El Golf una solicitud de aborto terapéutico, en atención a lo establecido por la Resolución ministerial 486-2014-MINSA, que aprobó la Guía Técnica de Aborto Terapéutico.

Pese a lo anterior, la denunciada no cumplió con convocar a la Junta Médica que se encargaría de evaluar su caso, y mucho menos cumplió con atender su solicitud de aborto terapéutico dentro del plazo establecido en la Guía Técnica. Ante ello, optó por acudir el 26 de diciembre de 2014 al Instituto Perinatal,

\footnotetext{
9 El síndrome de Turner es un trastorno genético que afecta el desarrollo de las niñas. La causa es un cromosoma $X$ ausente 0 incompleto. Las niñas que lo presentan son de baja estatura y sus ovarios no funcionan en forma adecuada. La mayoría de las mujeres con síndrome de Turner son infértiles. Corren el riesgo de tener problemas de salud como hipertensión arterial, problemas renales,
}

lugar donde se le practicó un aborto con fines terapéuticos.

Mediante correo electrónico del 30 de enero de 2015, Clínica El Golf, le comunicó que había sido informada sobre el diagnóstico, pronóstico y riesgos que su embarazo implicaba, sin embargo, ello no era cierto, y luego de revisar su historia clínica advirtió que en ella no se consignó su solicitud de aborto terapéutico.

\section{b. Resolución de Primera Instancia}

Mediante Resolución 2243-2016/CC1 de fecha 26 de octubre de 2016, la comisión de Protección al Consumidor emitió el siguiente pronunciamiento:

i. Declaró INFUNDADA la denuncia interpuesta contra la clínica El Golf por presunta infracción de los artículos $1^{\circ}$ numeral 1 literal b); $2^{\circ} ;$ y $67^{\circ}$ numeral 4 literal b) del Código, al haberse acreditado que la denunciada brindó información a la denunciante sobre la finalidad de los exámenes practicados (preoperatorio, riesgo quirúrgico y ecografía pélvica)

ii. Declaró INFUNDADA la denuncia interpuesta contra la clínica El Golf por presunta infracción de los artículos $18^{\circ} ; 19^{\circ} ; \mathrm{y}, 67^{\circ}$ numeral 1 del Código, en el extremo referido a no haber tramitado debidamente la solicitud de aborto terapéutico presentada por la denunciante, al haberse acreditado que la denunciada no estaba obligada a: (a) responder tal solicitud dentro del plazo establecido; (b) convocar una Junta Médica para efectuar su evaluación; (c) incluir dicha solicitud en la Historia Clínica; y, (d) realizar el procedimiento de aborto terapéutico.

iii. Declaró INFUNDADA la denuncia interpuesta contra Clínica El Golf por presunta infracción de los artículos $18^{\circ}$ y $19^{\circ}$ del Código, en el extremos referido a la omisión de brindar información sobre el diagnóstico, pronóstico y riesgos graves que el embarazo de la paciente conllevaba, al haberse acreditado que la denunciante brindó tal información a la denunciante; y,

iv. Desestimó la solicitud de medidas correctivas y de pago de costas y costos presentada por la denunciante.

Así pues, la Comisión fundamentó dicha decisión en que, la solicitud de aborto terapéutico fue presenta por la denunciante, y no, conforme lo establecía la Guía

diabetes, cataratas, osteoporosis y problemas tiroideos. Obtenido de la página web de Medline Plus, un servicio de la biblioteca Nacional de Medicina de EE.UU, disponible en https://medlineplus.gov/spanish/turnersyndrome.html 
Técnica de Aborto Terapéutico, esto es, por su médico tratante:

Sobre la falta de respuesta a la solicitud de aborto terapéutico dentro del plazo legal establecido

(...) Teniendo en cuenta lo indicado, se aprecia que en el presente caso no se cumplió con el primer requisito establecido en la Guía para que se pueda presentar una solicitud de aborto terapéutico por una gestante, a saber, determinar o diagnosticar que la paciente presenta uno de los problemas de salud indicados en la Guía y que dicha patología pone en riesgo su salud o su vida, por lo que la clínica no se encontraba en la obligación de brindar una respuesta en el requerimiento de aborto terapéutico formulado por la denunciante. (Resolución 2243-2016/CC1, fundamento 48).

Sobre la conformación de una Junta Médica y el rechazo de la solicitud de aborto terapéutico

(...) Respecto a estos extremos de la denuncia, cabe señalar que al haber quedado establecido que en el presente caso no se cumplió con el procedimiento señalado por la Guía para la realización del aborto terapéutico, ello tanto en tanto que el médico de la denunciante no consideró que su embarazo pusiera en riesgo su salud o su vida, la Clínica no se encontraba obligada a convocar a una Junta Médica o aceptar la solicitud de aborto terapéutico. (Resolución 2243-2016/CC1, fundamento 53)

Sobre la no inclusión de la solicitud de aborto terapéutico en la Historia Clínica

(...) Sobre este extremo de la denuncia, cabe señalar que, tal como se ha indicado previamente, al haber quedado establecido que en el presente caso no se cumplió con el procedimiento señalado por la Guía para la realización del aborto terapéutico en tanto que el médico de la denunciante no consideró que su embarazo calificaba como un supuesto establecido en dicho documento y ponía en riesgo su salud o su vida, la Clínica no se encontraba obligada a tramitarla y, por ende, tampoco a integrarla a la Historia Clínica de la denunciante. (Resolución 2243-2016/CC1, fundamento 57).

\section{c. Recurso de apelación}

Respecto al recurso de apelación, el Tribunal de Indecopi consideró que el hecho referido a no haber tramitado debidamente la solicitud de aborto terapéutico, subsumía las demás conductas imputadas, de tal manera que no solo se debió analizar si la denunciante siguió el procedimiento establecido en la Guía Técnica, sino también si, luego de presentada la mencionada solicitud, la Clínica actuó de manera idónea o no.

En tal sentido, el Tribunal de Indecopi realizó un análisis respecto a los deberes de información y de idoneidad que debió cumplir la Clínica El Golf en el presente caso:

\section{Sobre el deber de información}

(...) Es oportuno mencionar que la propia señora señaló, a través de su escrito de denuncia que, Clínica El Golf cumplió con informarle, antes de ser hospitalizada, que su diagnóstico definitivo se correspondía con amenaza de aborto y embarazo de alto riesgo. (Resolución 1884-2017/SPCINDECOPI, fundamento 28).

Por otro lado, de la revisión de la Historia Clínica de la Señora, se aprecia que su médico ginecólogo tratante -el Dr. Almeyda- ordenó la realización de un chequeo preoperatorio, un examen de riesgo quirúrgico y una ecografía pélvica. (Resolución 1884-2017/SPC-INDECOPI, fundamento 29)

De la misma manera, se advierte que se realizó una interconsulta con el área de cardiología de la Clínica El Golf y se le explicó a la consumidora cuál era el plan de trabajo, tal y como lo evidencia la anotación consignada en su Historia Clínica. (Resolución 1884-2017/SPC-INDECOPI, fundamento 30)

De lo expuesto, se colige que la señora Borgoño no solo conocía cuál era su diagnóstico, sino también cuál era el Plan de Trabajo previsto por el Dr. Almeyda para reducir la amenaza de aborto existente. (Resolución 1884-2017/SPC-INDECOPI, fundamento 31)

El Tribunal de Indecopi confirmó la resolución 22432016/CC1, en el extremo de haber declarado infundada la denuncia interpuesta contra la Clínica El Golf por presunta infracción de los artículos $1^{\circ}$ numeral 1 literal b); $2^{\circ}$; y $67^{\circ}$ numeral 4 literal b) del Código, al haberse acreditado que la denunciada brindó información a la denunciante sobre la finalidad de los exámenes que se le practicó, esto es, preoperatorio, de riesgo quirúrgico y el de ecografía pélvica.

Sobre el deber de idoneidad

Respecto al deber de idoneidad, se le imputó a Clínica El Golf la comisión de dos (02) presuntas infracciones:

(i) no haber tramitado debidamente la solicitud de aborto terapéutico y (ii) haber omitido consignar en la Historia Clínica la información sobre el diagnóstico, pronóstico y riegos graves que el embarazo de la paciente conllevaba. 
No haber tramitado debidamente la solicitud de aborto terapéutico:

La Sala consideró que:

En el caso en concreto, no corresponderá determinar si el aborto terapéutico realizado a la denunciante en el Instituto Perinatal fue correcto -o no-, o si el Dr. Almeyda consideró debidamente que el embarazo de la señora no ponía en riesgo su vida o causaba un mal grave y permanente en su salud. Hacerlo, supondría a cuestionar el análisis efectuado por el médico tratante e ir en contra de su opinión o criterio especializados. (Resolución 1884-2017/SPCINDECOP, fundamento 67).

Clínica El Golf debió haber derivado la solicitud de fecha 18 de diciembre de 2014 al Dr. Almeyda, a fin de que este último evalué si el embarazo de la señora Borgoño causaba un grave y permanente daño a su salud mental, tal y como concluyó la Dra. Rondón. (Resolución 1884-2017/SPCINDECOP, fundamento 76)

En ese orden de ideas, Clínica El Golf debió considerar, luego de evaluar la solicitud de aborto terapéutico presentada por la señora Borgoño, las posibles afectaciones graves y permanentes que su embarazo podría ocasionar no solo en su salud física, sino también en su salud mental. Ello, en la medida que el derecho a la salud mental es un derecho fundamental de la denunciante cuyo sustento se encuentra contenido en el principio-derecho de dignidad humana y en el derecho a la salud. Para ello es imperativo ver integralmente al ser humano: como una unidad física y psíquica, con la finalidad de cautelar su desenvolvimiento vital dentro de unas condiciones mínimas de dignidad. (Resolución 1884-2017/SPC-INDECOP, fundamento 82)

Así, el Tribunal de Indecopi revocó la resolución venida en grado en el extremo que declaró infundada la denuncia contra Clínica El Golf por haber infringido los artículos $18^{\circ}, 19^{\circ}$ y $67^{\circ}$ numeral 1 del Código, por haberse acreditado que la denunciada no tramitó adecuadamente la solicitud de aborto terapéutico.

Haber omitido consignar en la Historia Clínica la información sobre el diagnóstico, pronóstico y riegos graves que el embarazo de la paciente conllevaba

(...) se advierte que, tanto el 6 como el 10 de diciembre de 2014, se consignó en la Historia Clínica de la señora Borgoño que el personal médico de la denunciada explicó a la consumidora, y a su cónyuge, por un lado, cuál era el plan de trabajo previsto para reducir la amenaza de aborto que presentó (tal plan de trabajo incluía la relación de exámenes y las interconsultas a realizar) y, por otro lado, cuál propiamente el diagnóstico que se correspondía con su cuadro clínico. (Resolución 18842017/SPC-INDECOP, fundamento 89)

En tal sentido, el Tribunal confirmó la resolución venida en grado en el extremo que declaró infundada la denuncia contra Clínica El Golf por presunta infracción de los artículos $18^{\circ}$ y $19^{\circ}$ del Código, por haber omitido brindar información a la denunciante sobre el diagnóstico, pronóstico y riesgos que conllevaba su embarazo, pues al haber revisado la historia clínica se corroboró que la clínica cumplió con brindar dicha información a la consumidora.

d. Análisis

Corresponde analizar el fallo emitido por el Tribunal de Indecopi y las razones en las que se amparó para sostener que la Clínica El Golf no cumplió con su deber de idoneidad en su calidad de proveedor.

Como ya se ha mencionado, se le imputó a Clínica El Golf la comisión de dos (02) presuntas infracciones: (i) no haber tramitado debidamente la solicitud de aborto terapéutico y (ii) haber omitido consignar en la Historia Clínica la información sobre el diagnóstico, pronóstico y riegos graves que el embarazo de la paciente conllevaba.

Respecto a la segunda infracción no es necesario referirnos, ya que compartimos la decisión del Tribunal, toda vez que, se logró demostrar que en la Historia Clínica de la denunciante sí se consignó la información sobre el diagnóstico, pronóstico y riesgos que conllevaba su embarazo, además de la información sobre los exámenes que se le practicó.

No obstante, discrepamos en la decisión de haber declarado fundada la denuncia en el extremo de no haber tramitado debidamente la solicitud de aborto terapéutico, por las siguientes razones:

a) Procedimiento para acceder a la interrupción voluntaria por Indicación terapéutica del embarazo En el apartado 6. 2 de la Guía Técnica se establece claramente el procedimiento que se debe seguir para poder acceder a un aborto terapéutico. En tal sentido, este procedimiento se inicia cuando el médico tratante advierte que el embarazo pone en riesgo la vida de la gestante o causa en su salud un mal grave $y$ permanente.

El/La médico/a tratante que durante la atención de la gestante advierta que el embarazo pone en riesgo la 
vida de la gestante o causa en su salud un mal grave y permanente, informará a la embarazada sobre el diagnóstico, el pronóstico, los riesgos graves para su vida o su salud, y los procedimientos terapéuticos que correspondan. (Resolución Ministerial N4862014/MINSA, aparatado 6.2.1)

Sin embargo, en el caso bajo análisis observamos que el Dr. Almeyda (médico tratante) consideraba que era innecesario practicarle un aborto terapéutico a la denunciante, en la medida que no se encontraba en riesgo su vida y tampoco podría ocasionarle un mal grave y permanente en la salud de la gestante. Por lo tanto, no podríamos hablar de falta de idoneidad en la prestación de servicios de salud (obstétricos) ${ }^{10}$, cuando es el médico quien considera que no se cumple el primer presupuesto para que la gestante acceda a un aborto terapéutico. Así pues, es el médico tratante el único facultado para determinar -basándose en criterios científicos y especializados - si un embarazo pone en riesgo la vida o causa un mal grave $y$ permanente en la salud de la gestante, de tal manera que así se evite una propagación de solicitudes de aborto terapéutico cuando las circunstancias no lo ameritan ni justifican.

La denunciante presentó la solicitud de aborto terapéutico ante la dirección general de la Clínica El Golf adjuntando el certificado psiquiátrico emitido por la Dra. Rondón. El Tribunal considera que el Dr. Almeyda debió evaluar nuevamente si el embarazo de la señora causaba un mal grave y permanente en su salud tomando en cuenta el certificado psiquiátrico de la Dra. Rondón. Sin embargo, era muy difícil que el Dr. Almeyda pudiera conocer dicho certificado, pues la denunciante presentó la solicitud ante la Dirección General, y no ante su médico tratante para que este pueda evaluar si existía un "posible peligro", pues era él el más idónea para valorar su situación y no la Dirección General. Sin perjuicio a ello, llama la atención que tan solo un día después de haber sido dada de alta, la denunciante acuda a su psiquiatra y esta en una sola sesión pueda

10 SANNA/ CLÍNICA EL GOLF ofrece servicios de Servicio de Emergencia 24 hrs: Servicio implementado con todos los equipos necesarios para una atención efectiva y oportuna. Cuenta con una Unidad de Trauma Shock y tópico para cirugía menor y politraumatizados, brindando atención médica en Pediatría, Medicina Interna, Cirugía y Cardiología con presencia médicos especialistas las 24 horas del día. Consulta ambulatoria en más de 30 especialidades. Farmacia. Laboratorio clínico y patología. Anestesiología: Contamos con un equipo integrado por especialistas calificados en analgesia, terapia del dolor y reanimación; se encargan de monitorear y administrar anestésicos que permiten cuidar del paciente antes, durante y después de un emitir un diagnóstico tan concluyente como el de depresión recurrente con reacción de adaptación al estrés, indicándole además que, su gestación suponía un riesgo severo para su salud mental. Asimismo, como señaló la Clínica el golf "es lógico saber que, si un paciente necesita terapia psicológica, este requiere un tratamiento que toma cierto tiempo para poder establecer un diagnóstico certero (...) igualmente, es extraño conocer que la denunciante tenía antecedentes sintomatológica depresiva desde los 21 años de edad cuando en su Historia Clínica no se cuenta con dicha información"11.

b) Respecto a la causal aludida:

La gestante solicitó que se le practique un aborto terapéutico aludiendo la causal número once establecida en la Guía técnica, la misma que señala:

Cualquier otra patología materna que ponga en riesgo la vida de la gestante o genere en su salud un mal grave y permanente, debidamente fundamentada por la Junta Médica. (Resolución Ministerial N486-2014/MINSA, aparatado 6.1, numeral 11)

Esta cláusula otorga un amplio margen de interpretación para que se pueda aceptar una solicitud de aborto terapéutico, pues -como se verá más adelante- bastará que se le alegue una afectación a la salud mental de la gestante o -como en el caso bajo análisis- presentar un certificado psiquiátrico para sustentar dicha práctica, aun cuando las razones no justifiquen la intervención.

Como se ha señalado líneas arriba, un claro ejemplo de la subjetividad y amplitud que presenta esta cláusula es la postura de la autora Moz Saco (2018) al proponer la inclusión del aborto eugenésico dentro de los supuestos impunes de aborto terapéutico, al sostener que:

Con la prohibición del aborto de un feto con malformaciones congénitas que hacen imposible su sobrevivencia no solo se afecta la salud física de la mujer, sino también resulta afectada su salud mental,

procedimiento quirúrgico, diagnóstico para aliviar el dolor. Cardiología invasiva. Servicio de terapia física. Centro de Imágenes: Cineangiografía, Ecografía y ecografía obstétrica Enteral y parental, Tomografía, rayos X y Resonancia. Unidad de cuidados intensivos neonatales: Implementada con tecnología diseñada íntegramente para brindar al recién nacido, atención y cuidados altamente especializados que permitan su mejor y más pronta recuperación. Centro Oncológico ALIADA: El centro oncológico más moderno del país. Único con Certificación Internacional Accreditation Association for Ambulatory Health Care AAAHC. Disponible en: https://sanna.pe/clinicas/el-golf-lima/servicios.

${ }^{11}$ Escrito de descargos de la Clínica el Golf, p. 30. Disponible en: http://www.gacetajuridica.com.pe/boletin-nvnet/img_bol08/1007-2017-clinica-el-golf-aborto-terapeutico1.pdf. 
ya que se podrían generar graves consecuencias para el desarrollo de su vida futura, incluyendo el resto de su familia (p.87).

Como se observa, esta causal genera un sinfín de "razones" para que la gestante pueda solicitar la interrupción voluntaria de su embarazo, a pesar de que en dichos casos no sea necesaria dicha práctica. En tal sentido, al ser el aborto terapéutico una medida excepcional en nuestro ordenamiento jurídico, los requisitos para su acceso deben ser muy específicos y concretos, de tal manera que no exista posibilidad de aplicarlo en situaciones donde no hay una razón justificada.

c) Objeción de conciencia en las prácticas de aborto terapéutico:

A pesar de que en la resolución mencionada no se aborda el tema de la objeción de conciencia, conviene traerlo a colación para analizarlo como un caso hipotético frente a las tan amplias causales que se han regulado en el P.A.T, específicamente la referida a la salud mental de la gestante, pues el personal médicobasándose en sus conocimientos especializados- puede advertir que las causales expuestas en la Guía técnica no justifican o son innecesarias para poder acceder a un aborto terapéutico, y así desistir de realizar estas prácticas por considerar que atentan contra sus valores, su ética o moral. No obstante, la interpretación realizada por el Tribunal de Indecopi, generaría consecuencias en el personal de salud como el limitar el ejercicio de su derecho a la objeción de conciencia frente a prácticas que atentan contra la vida del ser humano -atendiendo a las causales señaladas en el protocolo-, así como también, el hecho de que las clínicas no contraten los servicios de médico objetores de conciencia, toda vez que un Tribunal- alegando falta de idoneidad en la prestación de sus servicios- puede sancionarlos en su calidad de proveedores.

\section{L ABORTO TERAPÉUTICO DESDE LA PERSPECTIVA DE LA OBJECIÓN DE CONCIENCIA EN LOS SERVICIOS PRIVADOS DE SALUD}

\subsection{El aborto terapéutico en la legislación peruana}

El aborto terapéutico pertenece a una de las clases de aborto provocado o inducido, esto es cuando existe intervención humana en la muerte o destrucción de la vida del concebido. Pacora- Portella (2014) lo define como "la interrupción voluntaria de un embarazo antes de la viabilidad fetal (22 semanas o menos de $500 \mathrm{~g}$ ), por razones de salud materna" (p.236). No obstante, el autor también señala que “(...) la denominación de 'aborto terapéutico' no se ajusta a la realidad, ya que ningún aborto tiene la propiedad intrínseca de curar o mejorar el estado de salud de la mujer." (p. 236).

Por su parte Besio et al. (2008) señala que el aborto terapéutico supone

"interrupciones del embarazo en las cuales lo que se persigue finalmente es la salud de la madre en su sentido amplio. Se trata de aquellos casos en que la muerte del embrión o feto es buscada como medio para lograr la salud materna" (p.9).

Así pues, podemos afirmar que el aborto terapéutico implica en términos generales acabar con la vida del concebido cuando el médico considera que la continuidad de su vida en el vientre materno pone en peligro la salud física o psicológica de la gestante, ponderando de esta manera la vida o salud de la mujer gestante sobre la vida del concebido.

Por otro lado, nuestro Código Penal regula en su artículo 119 el aborto terapéutico señalando que

"no es punible el aborto practicado por un médico con el consentimiento de la mujer embarazada o de su representante legal, si lo tuviere, cuando es el único medio para salvar la vida de la gestante o para evitar en su salud un mal grave y permanente". Así, el legislador no ha creído conveniente eliminar el aborto terapéutico como uno de los delitos que se encuentra bajo el título I de delitos contra la vida el cuerpo y la salud, por lo tanto no podemos hablar de una legalización de este tipo de aborto, toda vez que continúa siendo un delito, pero claro está- no punible.

Asimismo, resulta pertinente señalar que, a partir de la aprobación de la "Guía Técnica Nacional para la estandarización del procedimiento de la Atención Integral de la gestante en la Interrupción Voluntaria por Indicación Terapéutica del Embarazo menor de 22 semanas con consentimiento informado en el marco de lo dispuesto en el artículo 119o del Código Penal" a través de la Resolución Ministerial N 486-2014/MINSA, se reguló el mal llamado aborto terapéutico, creando así un conflicto en el sistema jurídico peruano debido a las causales expuestas para que la gestante pueda solicitar y acceder a dicha práctica, las mismas que han siendo objeto de múltiples reproches.

En este escenario, se presenta un conflicto de bienes jurídicos, por un lado tenemos el aborto como derecho de la mujer, y del otro lado, el derecho a la vida del concebido. Ello surge en Perú como consecuencia de la despenalización del aborto terapéutico y la aprobación del P.A.T, situación que ha sido reconocida por algunas 
organizaciones como un esfuerzo del Estado para garantizar una maternidad voluntaria, libre y segura. ${ }^{12}$ Mientras que, desde el punto de vista de la dogmática penal, "la sola referencia a que el denominado aborto terapéutico no es punible, podría conducir a afirmar que estemos ante una causa o condición que afecta la punibilidad (condición objetiva de punibilidad o excusa absolutoria)". (Oré, 2014, p. 2). Sin embargo, dicho supuesto continúa siendo un comportamiento antijurídico, al que debido a su excepcional situación motivacional -único medio para salvar la vida de la gestante o para evitar en su salud un mal grave y permanente- se le excluye de responsabilidad.

Sin embargo, de la lectura de las causales contenidas en el mencionado protocolo, podemos advertir que las mismas no cumplirían con la finalidad para la cual fueron creadas, sino que, muy por el contrario se estaría utilizando esta figura para justificar la interrupción del embarazo, aun cuando de por medio no exista una verdadera causa.

Un claro ejemplo de ello es lo manifestado por $\mathrm{Moz}$ (2018), quien considera que las causales establecidas en el protocolo no son suficientes, sino que para ella resulta necesaria la subsunción del tipo penal de aborto eugenésico dentro del supuesto de aborto terapéutico, del tal manera que la gestante pueda solicitar la interrupción de su embarazo cuando el feto presente malformaciones congénitas que cause una afectación a su salud mental. ${ }^{13}$

Así pues, con la no punibilidad del aborto terapéutico se estaría permitiendo abiertamente la práctica de un sinnúmero de abortos, cuya aceptación implicaría alegar un aparente derecho a la salud física y psicológica de la gestante, olvidando así los verdaderos e inviolables derechos de aquellos seres que se encuentran en un mayor estado de indefensión debido a su estado prematuro. En tal sentido, nos estaríamos amparando en una realidad sumamente excepcional como la del aborto terapéutico para justificar situaciones en las que no existiría una verdadera causa, siendo una de ellas la salud psisológica de la gestante, pues como afirma Silva (2014) "a la postre todo aborto se convierte en terapéutico, porque acaba considerándose que el simple rechazo de la madre a tener el hijo que lleva en su vientre, constituye una situación grave para su salud psíquica" (p.61).

12 Cfr. Pronunciamiento de diversas organizaciones como Demus, Movimiento Manuela Ramos, Centro de la Mujer Peruana Flora Tristán, Promsex (2014). Disponible en http://www.flora.org.pe/web2/images/stories/bonnie/PDF/Pronu nciamiento.pdf.

${ }^{13}$ Cfr. Moz, K. (2018). La inclusión del aborto eugenésico dentro de los supuestos impunes de aborto terapéutico para evitar una
Así pues, no resulta nada alejado de la realidad la interpretación del autor al señalar que a la larga cualquier "excusa" de la gestante terminaría convirtiéndose en un peligro grave y permanente para su salud psicológica, escenario que evidencia un riesgo muy preocupante, pues "ya la historia de multitud de países ha demostrado que el llamado aborto terapéutico es solo el primer paso para su total liberalización" (Silva, 2014, p.54). Tal es el caso de Estados Unidos, en donde el aborto no era legal, excepto en aquellos casos en donde se ponía en peligro la vida de la madre (aborto terapéutico), sin embargo años más tarde, en 1973 a consecuencia del fallo emitido por la Corte Suprema de Estado Unidos en el caso Roe vs. Wade, se despenalizó en su totalidad el aborto. ${ }^{14}$

Volviendo al protocolo de aborto terapéutico, nos preguntamos: ¿qué se entiende como el único medio para salvar la vida de la gestante? ¿En qué casos seguir con el procedimiento de la gestación afecta la salud física o psicológica de la madre? ¿Por qué se debe priorizar una vida sobre la otra? ¿Acaso el médico no tiene la responsabilidad de salvar vidas y no la de acabar con ella?

En la guía se establece que su aprobación obedece a un objetivo concreto, el mismo que se traduce en la estandarización de los procedimientos para la atención integral de la gestante en los casos de Interrupción Voluntaria por Indicación Terapéutica del Embarazo menor de veintidós semanas con consentimiento informado, cuando es el único medio para salvar la vida de la gestante o para evitar en su salud un mal grave y permanente, conforme dispone el artículo 119o del Código Penal y normas legales vigentes.

No obstante, la mencionada guía no define, ni mucho menos hace una diferencia de cuándo nos encontramos en un supuesto en donde la interrupción sea el único medio para salvar la vida de la gestante y en qué circunstancias se busca evitar en la salud de la madre un mal grave y permanente.

Asimismo, se hace mención que dicha alternativa debe ser puesta en conocimiento de la gestante afectada para que, de manera voluntaria e informada, pueda decidir si desea optar o no por la referida alternativa. Así pues, resulta evidente que el aborto terapéutico implica que es la gestante quien puesta en

grave afectación de la salud mental de la madre. Lima, Perú: Ed. Gaceta Penal \& procesal penal, p.85.

14 Cfr. Caso Roe vs. Wade disponible en: https://www.bbc.com/mundo/noticias-39017963. 
conocimiento por el médico; tiene el poder de decidir si continúa con el embarazo o por el contrario pone fin a la vida del concebido. Dicha situación se contrapone a lo establecido en la constitución y en el código civil, en donde se le reconoce al concebido como sujeto de derecho en todo cuanto le favorece, entonces si el concebido tiene derecho a la vida ¿por qué en este supuesto se le otorga -erróneamente- a la madre la facultad de decidir sobre él?

Tanto en la guía técnica de aborto terapéutico comoen el artículo 19 del código penal se establece los requisitos para que la gestante pueda solicitar la interrupción terapéutica del embarazo.

Sin embargo, el hecho de establecer estos parámetros o requisitos, no asegura que su acceso se dé en situaciones donde verdaderamente la vida de la madre esté en riesgo, máxime si las causales señaladas en el protocolo no se ajustan a su objetivo. Ante ello, Silva (2014) sostiene que "se equivocan quienes piensan que estableciendo requisitos para que los abortos terapéuticos sean una excepción muy calificada, se ataja el problema" (p.63).

En tal sentido, si bien la guía ha establecido requisitos y causales o situaciones en donde se amerita evaluar la interrupción del embarazo, esto no significa que aquellos justifiquen la misma, máxime si no se ha establecido con claridad la definición de cada una de ellas, pues debido a su poca precisión se podría inducir a una interpretación antojadiza para acceder a dicha práctica.

La guía ha establecido cuatro requisitos: (i) que sea el único medio para salvar la vida de la gestante o para evitar en su salud un mal grave y permanente, (ii) esta alternativa debe ser puesta en conocimiento de la gestante afectada para que, de manera voluntaria e informada, pueda decidir si desea optar o no por la referida alternativa, (iii) que el tiempo de embarazo sea menor a veintidós semanas y (iv) que la causal que amerite dicha práctica recaiga sobre cualquiera de los once supuestos regulados en la guía.

Respecto al primer requisito, que sea el único medio para salvar la vida de la gestante o para evitar en su salud un mal grave y permanente, sostiene PacoraPortella (2014) que "cualquier embarazo pone en peligro la salud de la madre y no por ello se deben interrumpir a todos los embarazos". (p.236)

Ante ello, resulta criticable que la guía no defina con exactitud qué debe entenderse o en qué situaciones se pone en un verdadero peligro la vida o salud de la madre, pues como señala el autor mencionado, todo

${ }^{15}$ Resolución Ministerial N 486-2014/MINSA. 6.1 La interrupción voluntaria (...) debe ser puestas en conocimiento de la gestante embarazo conlleva un riesgo para la madre, sin embargo, ello no quiere decir que nos encontremos en una situación de elegir por una u otra vida.

Asimismo, afirma Oré (2014) que:

En el estado actual de la medicina (...) se puede poner en tela de juicio que existan muchos casos en los que la continuación del embarazo suponga un real peligro para la vida de la madre. Más difícil aún, pensar que la práctica del aborto constituya el único medio para salvar la vida de la madre, o para evitar en ella un mal grave y permanente.

Así pues, resulta poco creíble que con el avance que ha tenido la ciencia hasta la actualidad nos encontremos en situaciones en donde el embarazo suponga o implique una grave y verdadera amenaza para la vida de la gestante, sin embargo, no negamos la posibilidad de que existen casos puntuales en donde la vida de la madre sí corre peligro, pero -claro está -su incidencia es mínima.

Sin embargo, como sostiene Silva (2014):

Sería mucho más honesto que los abortistas reconocieran abiertamente que su posición obedece a una mera arbitrariedad, a un puro deseo de -literalmente- desembarazarse de un "problema" y no querer asumir las consecuencias de sus actos cuando no les convienen o desagrada. Es más auténtico esto que justificar tal asesinato usando una bonita retórica, pretendiendo quitarle el estatuto de persona al feto, o ampliar el concepto de salud de la madre para hacerlos coincidir con este objetivo (p.38).

Respecto al segundo requisito, ello supone una relación médico - paciente, la misma que involucra dos agentes. Como afirma Pérez (2017)

Por un lado, está el paciente, quien es el principal responsable de su vida y su salud. Está consciente de su enfermedad y la amenaza que esta le supone para su autonomía, de sus límites e incompetencia para recuperar por su cuenta su salud o prevenir el daño que la enfermedad pudiere ocasionarle y por este motivo se dirige al otro agente: el médico. Este realiza la tarea de colaborador del paciente, haciendo uso de su preparación y experiencia médica, cuenta con la capacidad para ayudarlo (p.66).

En tal sentido, el consentimiento informado que se regula en el P.A.T ${ }^{15}$ exige dos relaciones médicopaciente, pues aun cuando el feto dependa de la madre para que sobreviva, este ya es considerado una persona distinto a ella, por lo que el médico tiene el deber de

afectada para que, de manera voluntaria e informada, pueda decidir si desea optar o no por la referida alternativa. 
colaborar con la recuperación de la salud de la madre y de su hijo.

Como vemos, se le otorga un gran valor al consentimiento de la gestante para la interrupción del embarazo como causa de justificación, empero "para que ello suceda se exige una cuestión fundamental: que el autor obre con consentimiento válido del titular de un bien jurídico de libre disposición (...) y es el caso que la madre gestante no es titular del derecho que se sacrifica" (Oré, 2014, p.5-6). En consecuencia, al no ser la titular del bien jurídico protegido (la vida del concebido) no puede decidir la interrupción del embarazo.

No obstante, el Protocolo de Aborto Terapéutico no reconoce la realidad del feto, en tanto que lo subsume a la madre y consecuentemente suprime sus derechos. Así pues, el legislador ha utilizado la denominación "contenido uterino" y "gestante" para aludir al feto y a la madre, respectivamente. Esto resulta incoherente, dado que para la existencia de la "gestante" hace falta que haya una vida humana desarrollándose en su vientre, con las denominaciones científicas correspondientes a cada etapa de su desarrollo vital (cigoto, mórula, blástula, feto).

Lo alarmante es que, en el acápite 6.3 del P.A.T se alude al procedimiento que realiza la Junta médica para evaluar si es factible o no la interrupción del embarazo, situación que llama la atención al otorgarle a la gestante la posibilidad de apelar en una segunda instancia -si en caso fue negada su solicitud por la primera junta-; solicitando al Director General del establecimiento de salud que se realice una nueva Junta Médica con otros médicos. Con ello, resulta evidente que lo que se busca con la regulación de este P.A.T, no es otra cosa que "el aborto por aborto", pues no resulta suficiente con la opinión de una primera junta, sino que otorga la posibilidad de que la gestante apele la decisión que le ha sido negada hasta que la acepten. ${ }^{16}$

Aunado a ello, cabe señalar que los derechos del padre no se estarían considerando- a pesar de haber contribuido también en la creación del nuevo ser-, ya que la decisión de interrupción del embarazo solo recaen en la gestante y en la Junta médica encargada de evaluar la misma.

\footnotetext{
16 Resolución Ministerial N 486-2014/MINSA, 6.3.4 "Si la Junta Médica concluye que no es recomendable proceder a la interrupción terapéutica del embarazo menor de veintidós (22) semanas, el médico/a tratante comunicará a la gestante la decisión y las razones para ello. La gestante podrá solicitar al Director General del establecimiento de salud que se realice una nueva Junta Médica con otros médicos, la misma que deberá llevarse a cabo en un plazo no mayor de cuarenta y ocho (48) horas, bajo responsabilidad. En este caso el Director General del
}

Por otro lado, en cuanto al tercer requisito ${ }^{17}$, se requiere que la edad gestacional del feto sea menor a las veintidós semanas, es decir hasta los cinco meses y medio aproximadamente. Como podemos notar, la edad del feto exigida en el protocolo coincide con el límite de tiempo que ha establecido la OMS para referirnos a la no viabilidad fetal.

Sin embargo, la clave no está en cuál meta o requisito cumpla ese ser humano en su desarrollo (que se insiste, es arbitrariamente cambiable a voluntad), sino en el comienzo de este proceso: la concepción, aquel momento primigenio en el cual se inicia un desarrollo generado desde sí mismo, que si no se estorba, llegará a cualquiera de esas metas que se imponen. (Silva, 2014, p39).

Así pues, el hecho de establecer un límite (edad gestacional del feto) para que la gestante pueda solicitar la interrupción del embarazo; no constituye un argumento razonable ni suficiente para justificar dicha práctica, toda vez que se estaría haciendo una diferencia determinante entre un feto menor a las veintidós semana (a quien sí se podría abortar) con un feto mayor a la edad señalada (a quien no se podría abortar), pretendiendo así, privarlo de su calidad de persona.

Por lo tanto, como manifiesta Tomás y Garrido (2006) "todo aborto procurado es el asesinato injusto e inicuo de un ser humano. Incluso desde el punto de vista meramente biológico, no puede aducirse a la viabilidad como si este definiese a la persona" (p.98).

En tal sentido, este requisito no hace más que desconocer el inicio de la vida humana (fecundación) otorgándole más valor a una determinada etapa del nuevo ser, sin considerar que este ya forma parte de la especie humana- y no potencialmente- y que, consecuentemente se le debería reconocer el derecho a vivir.

Finalmente, resulta necesario estudiar las causales contempladas en el P.A.T., mediante las cuales se permitirá evaluar la posibilidad de que la gestante pueda solicitar la interrupción de su embarazo. De esta forma, podremos evidenciar la peligrosidad que supone para los objetores de conciencia dicha normativa.

Así pues, la solicitud de aborto terapéutico deberá ser alegada en base a cualquiera de las once causales

establecimiento de salud constituye y convoca por última vez a una segunda Junta Médica, pudiendo convocar a otros médicos/as especialistas del sector público o privado".

17 Resolución Ministerial N 486-2014/MINSA 6.1.La interrupción voluntaria por indicación terapéutica del embarazo menor de veintidós (22) semanas, es una alternativa que se considera cuando es el único medio para salvar la vida de la gestante o para evitar en su salud un mal grave o permanente. 
expuestas en el acápite 6.1 del P.AT. En cuanto a las dos primeros supuestos, es decir cuando se trate de un embarazo ectópico tubárico y mola hidatiforme parcial, "todo médico especialista en ginecología y obstetricia sabe que no se requiere realizar junta médica para tratarlo (...) pues, al comprometer la salud de la madre, debe ser interrumpido por razones médicas" (PacoraPortella, 2014, p.237).

En el primer supuesto, la implantación ocurre en un sitio fuera del endometrio normal, usualmente en las trompas de falopio, por lo que los embarazos ectópicos no pueden llevarse a término y finalmente ocurre su rotura. El segundo supuesto, se trata de una masa o tumor poco común que se forma en el interior del útero, en donde también puede haber un feto, pero no hay posibilidades de que sobreviva (Dulay, 2019). Por ende, resulta innecesario considerar a ambos supuestos como causales para solicitar la práctica de un aborto terapéutico, toda vez que en ninguno de estos casos se llega a desarrollar el feto.

Respecto a estas causales, Silva (2014) manifiesta que "es muy distinta la situación cuando habiendo reales problemas para la vida-no salud- de la madre (un embarazo tubario, una infección uterina grave, algunos casos de formación molar), los esfuerzos no se dirigen directamente a destruir al feto" (p. 62)

Es decir que, en estas situaciones aun cuando la vida de la madre se encuentra en un real peligro, no podríamos hablar propiamente de un aborto, pues sin duda el feto no podría desarrollarse y terminaría por morir, producto de un efecto indirecto.

Seguidamente, en cuanto a las causales contenidas en el numeral 3 hasta el 10, estas pueden ser tratadas de tal manera que no sea vea afecta la vida y salud de la madre, ni la de su hijo. Así pues, en el numeral 3 se menciona la hiperémesis gravídica refractaria al tratamiento con deterioro grave hepático y/o renal, el cual supone vómitos persistentes y tenaces en los primero días de gestación, sin embargo, esta puede ser tratada mediante el suministro de calorías (glucosa) o sedando a la gestante, y además con la administración de cortisona.

En cuanto a la Diabetes Mellitus gestacional, esta consiste en la intolerancia a la glucosa durante el embarazo, el cual puede ser tratado a través de dieta e insulina (Oré, 2014). Por lo que, en estos casos -al existir un tratamiento médico- no se debería optar por un aborto "terapéutico".

Finalmente, en la última causal se alude a cualquier otra patología materna que ponga en riesgo la vida de la gestante o genere en su salud un mal grave $y$ permanente, debidamente fundamentada por la Junta Médica. La redacción de esta causal admite un amplio e indeterminado margen de interpretación para que se pueda solicitar un aborto terapéutico, puesto a que no solo se considera el riesgo que puede correr la vida de la madre, sino también cualquier situación que genere un mal grave y permanente en su salud, entendida esta en su sentido más amplio. Ante ello, afirmar Tomás y Garrido (2006) que

"no se puede justificar la eliminación del hijo para evitar un agravamiento de la salud (...) pues lo que por ahora sí está claro es que ningún tipo de enfermedad se pueda curar solamente mediante el aborto, como tampoco es demostrable" (p.99)

\subsection{Objeción de conciencia y aborto terapéutico}

El derecho a la objeción de conciencia otorga "la posibilidad de excusarse de cumplir una ley, cuando esta violenta gravemente las convicciones y valores más fundamentales de una persona" (Silva, 2014, p.133). Esta posibilidad -que se da en situaciones límitetambién puede ser ejercida en el ámbito de la prestación de servicios de salud, cuando determinada práctica médica exige en el objetor el quebrantamiento de sus creencias religiosas, éticas o los dictados de su conciencia.

En ese sentido, "la objeción en el ámbito de la salud, se ha definido como la negativa de los profesionales sanitarios a cooperar o a ejecutar materialmente alguna intervención concreta que entra en colisión con sus imperativos de conciencia" (Beca y Astete, 2015, p.494) Y considerando que el aborto terapéutico -aprobado desde el 2014- exige que sea practicado por un personal médico, cabe preguntarnos ¿qué sucede con aquellos profesionales de la salud que se abstienen de realizar prácticas abortivas en razón de su conciencia? Pues, como sostiene Martínez (2007):

En el campo de la salud, la objeción de conciencia puede generar situaciones conflictivas entre el objetor y el solicitante de asistencia; entre el objetor y sus colegas; entre el objetor y su superior jerárquico; entre un jefe a su vez objetor y los demás miembros directivos de la institución sanitaria; otras derivadas de la reacción de las autoridades gestoras; y finalmente están las repercusiones en las relaciones entre los gestores y los políticos. Todo ello hace necesario justificar dicha objeción (p.220)

Así pues, al involucrarse en este supuesto una serie de intereses- dirigiéndonos al médico, a la gestante y a la clínica-, resulta necesario analizar si el hecho de que el profesional de salud ejerza su derecho a la objeción de conciencia frente a la práctica de un aborto terapéutico implica una falta de idoneidad en la prestación de sus servicios, o por el contrario se encuentra justificado. 
Habría que preguntarse si hay una afectación a la idoneidad de la prestación de los servicios de salud cuando un médico se niega a realizar un aborto terapéutico, pues como ya se ha definido, el deber de idoneidad al que se encuentra obligado la empresa proveedora (clínica) exige el hecho de brindar productos o servicios que correspondan a las características ofrecidas por el proveedor y esperadas por el consumidor, siendo que de no presentarse alguna de las causales de exclusión contempladas en el artículo $104^{\circ}$ del Código, será el proveedor quien resulte responsable por haber infringido el deber de idoneidad. Es decir que, el proveedor se encuentra obligado a respetar y cumplir con las condiciones y/o términos expresamente pactados con el consumidor, entendiéndose a la práctica del aborto terapéutico como parte de la idoneidad que deben cumplir las clínicas obstétricas.

No obstante, resulta preciso mencionar el caso de España, en donde pareciera que existe "un turismo del aborto, puesto que las reglas se manipulan a gusto del consumidor y de quien presta el servicio, cuyo precio aumenta según la edad gestacional del niño" (Silva, 2014, p.77), olvidándonos de esta manera qué significa ser un profesional médico y la función que cumple este dentro de una sociedad, así como la finalidad que debería cumplir la medicina como profesión.

En ese sentido, "el médico es una persona humana que tiene el conocimiento de cuidar y el arte de conservar la salud. La medicina, como profesión, es la aplicación del conocimiento del cuidado de la salud" (Pacora-Portella, 2014, p. 237)

Entonces, si el médico como profesional de salud tiene el deber de preservar y cuidar la vida y salud de sus pacientes, ello no se ajustaría con el contenido del P.A.T, toda vez que sus causales resultan innecesarias y poco razonables para justificar la interrupción de un embarazo, con lo cual se estaría acabando con la vida de uno de sus pacientes, el concebido.

$\mathrm{Si}$ los médicos pueden realizar operaciones intrauterinas con el objetivo de corregir algún tipo de patología que presenta el feto y con ello lograr que el

18 SANNA/ CLíNICA EL GOLF ofrece servicios de Servicio de Emergencia 24 hrs: Servicio implementado con todos los equipos necesarios para una atención efectiva y oportuna. Cuenta con una Unidad de Trauma Shock y tópico para cirugía menor y politraumatizados, brindando atención médica en Pediatría, Medicina Interna, Cirugía y Cardiología con presencia médicos especialistas las 24 horas del día. Consulta ambulatoria en más de 30 especialidades. Farmacia. Laboratorio clínico y patología. Anestesiología: Contamos con un equipo integrado por especialistas calificados en analgesia, terapia del dolor y reanimación; se encargan de monitorear y administrar anestésicos que permiten cuidar del paciente antes, durante y después de un paciente en su existencia extrauterina tenga una mejor vida, entonces resultaría ilógico desconocer su calidad de persona y por ende su derecho a la vida- otorgándole la facultad a la gestante de poder decidir si continúa o interrumpe el embarazo- en pos de otros intereses.

Consecuentemente, podemos afirmar que si bien el proveedor (clínica) debe cumplir con las expectativas y características ofrecidas al consumidor en la prestación del servicio, este debe hacerlo atendiendo a las circunstancias particulares que rodean al acto de consumo, y además de acuerdo al tipo de servicio o bien que se ha ofrecido. Así pues, en los servicios privados de salud lo que se busca es priorizar la salud del paciente (consumidor)- y no acabar con ella-, considerando no solo a la gestante, sino también al concebido, por lo que la idoneidad en estos casos no se verá afectada si el médico cumple con la finalidad de su profesión, el mismo que es el cuidado y la conservación de la salud de sus pacientes.

Entonces, llevando esta reflexión al caso de la clínica el golf, podemos advertir que dentro de los servicios ${ }^{18}$ que ofrecía no se encontraba el realizar estas prácticas, por ende no podríamos hablar de una falta de idoneidad si lo que la denunciante buscaba nunca fue ofrecido por dicha clínica.

Por lo tanto, podemos afirmar que, cuando el procedimiento médico atenta contra la vida y salud de las personas, entonces es posible que el profesional médico pueda ejercer su derecho a la objeción de conciencia sin afectar la calidad e idoneidad en la prestación de servicios de salud.

3.3 Criterios objetivos para ejercer debidamente el derecho a la objeción de conciencia cuando este se encuentra en un conflicto con el deber de idoneidad de las clínicas privadas de salud

Con la finalidad de brindar una respuesta coherente y razonable a la problemática planteada: ¿Cuáles serían los criterios objetivos a tomar en cuenta para ejercer el derecho a la objeción de conciencia cuando este se encuentra en un aparente conflicto frente a la idoneidad de la prestación de servicios de salud? y sobre

procedimiento quirúrgico, diagnóstico para aliviar el dolor. Cardiología invasiva. Servicio de terapia física. Centro de Imágenes: Cineangiografía, Ecografía y ecografía obstétrica Enteral y parental, Tomografía, rayos $X$ y Resonancia. Unidad de cuidados intensivos neonatales: Implementada con tecnología diseñada íntegramente para brindar al recién nacido, atención y cuidados altamente especializados que permitan su mejor y más pronta recuperación. Centro Oncológico ALIADA: El centro oncológico más moderno del país. Único con Certificación Internacional Accreditation Association for Ambulatory Health Care AAAHC. Disponible en: https://sanna.pe/clinicas/el-golf-lima/servicios. 
todo justificar nuestra postura, hemos considerado que los operadores de justicia deberían considerar que cuando el procedimiento médico atenta contra la vida y salud de las personas (como el aborto terapéutico), entonces es posible que el profesional médico pueda ejercer su derecho a la objeción de conciencia sin afectar la calidad e idoneidad en la prestación de servicios de salud.

Para llegar a esta respuesta, hemos aplicado el test de proporcionalidad como un instrumento que coadyuve en la prevalencia de un interés (practicar el aborto terapéutico a la gestante) frente al otro (el derecho a la objeción de conciencia del profesional médico para no realizar prácticas abortivas, ya sea terapéutica o no).

Así pues, el Tribunal Constitucional ha establecido en una de sus sentencias, recaída en el EXP.N. ${ }^{\circ}$ 579-2008PA/TC:

El test de proporcionalidad incluye, a su vez, tres subprincipios: idoneidad, necesidad y ponderación o proporcionalidad en sentido estricto. En cuanto al procedimiento que debe seguirse en la aplicación del test de proporcionalidad, hemos establecido que la decisión que afecta un derecho fundamental debe ser sometida, en primer término, a un juicio de idoneidad o adecuación, esto es, si la restricción en el derecho resulta pertinente o adecuada a la finalidad que se busca tutelar; en segundo lugar, superado este primer análisis, el siguiente paso consiste en analizar la medida restrictiva desde la perspectiva de la necesidad; esto supone, como hemos señalado, verificar si existen medios alternativos al adoptado por el legislador. Se trata del análisis de relación medio-medio, esto es, de una comparación entre medios; el medio elegido por quien está interviniendo en la esfera de un derecho fundamental y el o los hipotéticos medios que hubiera podido adoptar para alcanzar el mismo fin. Finalmente, en un tercer momento y siempre que la medida haya superado con éxito los test o pasos previos, debe proseguirse con el análisis de la ponderación entre principios constitucionales en conflicto. Aquí rige la ley de la ponderación, según la cual "cuanto mayor es el grado de la no satisfacción o de la afectación de un principio, tanto mayor tiene que ser la importancia de la satisfacción del otro.

En cuanto al principio de idoneidad, este supone que el derecho de la gestante de interrumpir su embarazo debido a que supuestamente este "es el único medio para salvar su vida o para evitar en su salud un mal grave y permanente", resulta pertinente restringirlo toda vez que- como ya se ha explicado-, las causales señaladas en el P.A.T no justifican dicha interrupción, ya que en ninguna de ellas se pone verdaderamente en peligro la vida de la gestante. Asimismo, aludir un daño a la salud de la gestante genera un amplio margen de interpretación para que la madre pueda solicitar dicha práctica, basándose en un daño a su salud psíquica o piscología, lo cual resulta muy subjetivo. Por ello, al no existir una causa razonable que justifique un aborto terapéutico sí se puede restringir este derecho con la finalidad de tutelar el derecho a la objeción de conciencia del profesional de salud para que este se pueda desistir de la realización de dicha práctica, toda vez que su ejecución va en contra de su conciencia, máxime si la finalidad de esta profesión es preservar la salud de sus pacientes (gestante y concebido) y no la de acabar directamente con una de ellas, en este caso el concebido.

Respecto al segundo principio, este sugiere analizar la medida restrictiva desde la perspectiva de la necesidad; verificando si existen medios alternativos al adoptado por el legislador. En ese sentido, la restricción del derecho de la gestante a que se le realice un aborto terapéutico resulta ser un medio necesario (indispensable) para alcanzar el objetivo propio de las prestaciones de servicio de salud (preservar la salud de la gestante y la del concebido, ya bajo las causales aludidas ninguna de ellas pone en peligro su vida). En tal sentido, no existen medidas alternativas igualmente eficaces o que sean menos gravosas que se dirijan a obtener el mismo fin, propios de los servicios de salud. Finalmente, en un tercer momento y siempre que la medida haya superado con éxito los test o pasos previos, debe proseguirse con el análisis de la ponderación. Aquí rige la ley de la ponderación, según la cual "cuanto mayor es el grado de la no satisfacción o de la afectación de un principio, tanto mayor tiene que ser la importancia de la satisfacción del otro. Como podemos notar, el grado de la no satisfacción de practicar un aborto terapéutico a la gestante que ha solicitado la interrupción de su embarazo alegando alguna de las once causales- ninguna de ellas pone en un verdadero e inminente peligro la vida de la madre, ni mucho menos su salud- establecidas en el P.T.A, es de baja o leve intensidad, frente a al ejercicio del derecho a la objeción de conciencia del profesional médicoorientado por los conocimiento propios de la ciencia médica-, toda vez que, sin dicha medida; el objetivo (prevalecer la vida de la gestante y del concebido) no sería posible de realiza, por lo tanto, dicha medida de restricción de leve intensidad logra niveles de satisfacción altos o elevados.

\section{Conclusiones}

El derecho a la objeción de conciencia supone una conducta omisiva e individual del sujeto, en el que se abstiene de obedecer o cumplir un mandato 
jurídicamente exigible, el mismo que puede provenir de un mandato legal, una resolución judicial, un acto administrativo, o un contrato. Asimismo, esta negativa no puede basarse en razones antojadizas del objetor, sino que deben estar motivadas en razones de su conciencia. Desde el ámbito de la prestación de servicios de salud, la objeción de conciencia es la negativa del profesional sanitario a ejecutar un acto médico o a cooperar directa o indirectamente a su realización porque a pesar de haber sido aprobado por las normas legales, es considerado por el profesional como contrario a su conciencia.

El deber de idoneidad forma parte de las obligaciones de todo proveedor en cumplir con los ofrecimientos efectuados al consumidor, de tal manera que se cumpla con las expectativas de este en relación a la calidad, uso, duración, origen, contenido y otras características propias de los productos o servicios contratados. No obstante, el proveedor debe cumplir con las expectativas generadas en el consumidor atendiendo a las circunstancias particulares que rodean al acto de consumo, y además de acuerdo al tipo de servicio o bien que se ha ofrecido, negociado y finalmente contratado. Así pues, en los servicios de salud lo que se busca es priorizar la salud del paciente (consumidor), considerando no solo a la gestante, sino también al concebido, por lo que la idoneidad en estos casos se verá reflejada siempre que los actos y/o prácticas realizadas por el profesional médico estén destinadas a cuidar y conservar la salud de los pacientes.

En la guía técnica de aborto terapéutico se establecen cuáles son los requisitos y las once causales para que la gestante pueda solicitar la interrupción terapéutica de su embarazo. No obstante, alguno de estos requisitos y causales resultan innecesarias y, además dejan un amplio margen de interpretación para que la gestante pueda solicitar -con argumentos poco razonables- la interrupción de su embarazo, situación que genera en muchos profesionales de salud una negativa en la realización de estas prácticas, por lo que haciendo uso de su derecho a la objeción de conciencia pueden optar por su desistimiento sin que ello implique una afectación al deber de idoneidad al que se encuentra obligada toda clínica privada de salud en su calidad de proveedora.

En el caso de la Clínica el golf, si bien no se aborda el tema de la objeción de conciencia, este escenario resulta ideal para evaluar a partir de él las consecuencias y limitaciones que traería el ejercicio del derecho a la objeción de conciencia por parte del personal de salud a la luz de las causales reguladas en el Protocolo de Aborto Terapéutico, aludiendo específicamente al de la salud mental de la gestante como sucedió en el caso en mención, sin embargo, resulta preciso aclarar que dicha clínica no ofrecía en su publicidad la realización de prácticas abortivas con fines terapéuticos, por ende no podríamos subsumir dicha negatividad en una falta de idoneidad en la prestación de sus servicios.

Por ello, en los casos donde se presente un conflicto entre el ejercicio del derecho a la objeción de conciencia por parte de los profesionales de salud para abstenerse de realizar prácticas abortivas, frente al deber de idoneidad en la prestación de servicios de salud que toda clínica privada está obligada a garantizar a sus consumidores, los operadores de justicia deberían tener en cuenta que, cuando el procedimiento médico atenta contra la vida y salud de las personas (en este caso el concebido), entonces es posible que el profesional médico pueda ejercer su derecho a la objeción de conciencia sin que este suponga una afectación a la calidad e idoneidad en la prestación de sus servicios.

Bibliografía

Beca, J. y Astete, C. (2015). Objeción de conciencia en la práctica médica. Revista médica de chile, 143(4),493-498. Recuperado de https://scielo.conicyt.cl/scielo.php?script=sci ar ttext\&pid=S0034-98872015000400011.

Besio, M. (2008). Aborto terapéutico. Consideraciones médicas, éticas, jurídicas y del magisterio de la iglesia católica. Recuperado de: https://docplayer.es/3938818-Abortoterapeutico-dr-mauricio-besio-mons-fernandochomali-dr-jorge-neira-prof-angelavivanco.html.

Cajarville, J. (2014). Concepto de relación de consumo. Revista De La Facultad De Derecho, (22), 151-164. Recuperado de: https://revista.fder.edu.uy/index.php/rfd/article /view/204

Cavada, J., Weidenslaufer, C. y Harris, P. (2016) Profesionales o instituciones que pueden ejercer objeción de conciencia frente a la interrupción del embarazo: derecho comparad. Biblioteca del congreso nacional de chile. Recuperado de: https://obtienearchivo.bcn.cl/obtienearchivo?id =repositorio/10221/23866/2/libertad $\% 20 \mathrm{de} \% 20$ conciencia\%20Act\%20\%200ctubre\%202016\%2 Orev\%20PT\%201 Eval\%20(3).pdf.

Diaz, O. (2004). "Tribunal constitucional y objeción de conciencia en las relaciones laborales". Revista Pensamiento constitucional, 10(10) ,168-182. Recuperado de: 
http://revistas.pucp.edu.pe/index.php/pensamie ntoconstitucional/article/view/7669/7915.

Dulay, A (2019). Embarazo Ectópico. Manual MSD, versión para público general. Editorial Staff. Recuperado de

https://www.msdmanuals.com/es-

pe/hogar/breve-informaci\%C3\%B3n-salud-

femenina/complicaciones-delembarazo/embarazo-ect\%C3\%B3pico.

Espinoza, J. (2006). Derecho de los Consumidores. Lima, Perú: Rodhas.

Gómez, A. (2013). Objeción de conciencia y desobediencia civil. Facultad de ciencia jurídicas Universidad de la Rioja. Recuperado de: https://biblioteca.unirioja.es/tfe_e/TFE000234.p df.

Indecopi.(2006). Lineamientos de Protección al Consumidor. 5-44. Recuperado de https://www.indecopi.gob.pe/documents/20182 /747822/CC1+y+CPC+-+ILN+-.pdf/cd9a32a6-

$4 a a b-4 b 60-993 c-$

8bb3a202ad89?fbclid=IwAR1VrHfkL4Q7EEcl|9z mOZzrhkVr 2ThLwmfG6Uc4tEBqOhu5WbWKuE$\mathrm{p}-\mathrm{Q}$.

Llamazares Fernández, D. (2007). Derecho de la libertad de conciencia I. Pamplona, España: Ed. Aranzadi S.A.

Martinez, K. (2007). "Medicina y objeción de conciencia".Rev. Anales Sis San Navarra, 30(2), 215-223. Recuperado de http://scielo.isciii.es/scielo.php?script=sci arttex t\&pid=S1137-66272007000300006

Mosquera, S. (2005). El derecho de libertad de conciencia y de religión en el ordenamiento jurídico peruano. Lima, Perú: Ed. Palestra Editores S.A.C.

Moz, K. (2018). La inclusión del aborto eugenésico dentro de los supuestos impunes de aborto terapéutico para evitar una grave afectación de la salud mental de la madre. Lima, Perú: Ed. Gaceta Penal \& procesal penal.

Navarro, J. (2004). El derecho a la objeción de conciencia. Buenos Aires, Argentina: Ed. Ábaco de Rodolfo Depalma S.R.L.

Navarro-Valls, R. (2007). Derecho Eclesiástico del Estado Español. Navarra, España: Ed. Ediciones Universidad de Navarra S.A.

Northcote, C. (2013). Criterios del indecopi sobre el deber de idoneidad. Actualidad Empresarial,
(290), 1-4. Recuperado de http://aempresarial.com/servicios/revista/290 4 3 MNHWGFTWZFKSFEBQJGVHBSZAIIHDDNMPA TLHZFEYLOQQSRHCYC.pdf.

Oré, E. (2014). ¿Se encuentra el Protocolo del Aborto Terapéutico "en el marco de lo dispuesto en el artículo 119 del Código Penal"?. Recuperado de http://www.incipp.org.pe/archivos/publicacione s/el aborto terapeutico_2014.pdf

Pacora, P. (2014). Aborto terapéutico: ¿realmente existe?. Acta Médica Peruana, 31(4), 234-239. Recuperado de http://www.scielo.org.pe/scielo.php?script=sci arttext\&pid=S172859172014000400006\&lng=es\&tIng=es

Pérez, L. (2004). Derechos del consumidor. Buenos Aires, Argentina: Ed. Astrea de Alfredo y Ricardo Depalma S.A.

Pérez, B. (2017). Implicancias Ético Legislativas Del Consentimiento Informado En La Redacción Del Protocolo De Aborto Terapéutico Para La Madre Gestante (Tesis de maestría). Universidad Católica Santo Toribio de Mogrovejo. Lambayeque, Perú. Recuperado de: http://hdl.handle.net/20.500.12423/1305

Salazar, C. (2013). Los límites de la objeción de conciencia en el ordenamiento Jurídico Peruano (Tesis de pregrado). Universidad Católica Santo Toribio de Mogrovejo. Chiclayo, Perú.

Silva, M. (2014). Bioética. Una cuestión vital. Chile: Ed. Centro de Estudios Cultura Cristiana.

Stiglitz, R. (1993).Derechos y defensa del consumidor. Buenos Aires, Argentina: Ed. Depalma S.A.

Tomás y Garrido, G. (2006). Cuestiones actuales de bioética. Navarra, España: Ed. Universidad de Navarra, S.A.

Vinces, M. (2015). “El derecho a la objeción de conciencia en la ley de libertad religiosa peruana. Nociones previas y aproximación critica. Revista IUS, 1 (10), 1-19. Recuperado de http://publicaciones.usat.edu.pe/index.php/ius/ article/view/275.

STC. N 0895-2001-AA/TC

STC N06111-2009-PA/TC 